\title{
Then and now with environmental pollution and the broader social medicine in Europe
}

Our historial article in this issue is from AS Fairburn and Donald Reid, who was a pioneer researcher in respiratory disease at the London School of Hygiene, with comments from Walter Holland, who continued to lead and promote research in applied epidemiology with special reference to respiratory disease. A further six articles follow in this number relating to contemporary problems in asthma and cigarette smoking as special cases of air pollution problems, ranging from Asia to the Nordic countries, spanning the Mediterranean and Europe. One of these studies continues to add information to the discussion about the effects of early life experiences on later health.

The health services research papers cover both hospitals and the community, picking up one traditional lifestylethat of the Romany communities now called "travellers". In another place I will be discussing how the protection of the collective rights of such communities may be fundamental in maintaining their health-that is, the public health of such cultural groups. ${ }^{1}$

Finally, two papers consider the effects of the labour market and of unemployment on the behaviour of doctors, and the self perception of the people involved. There can scarcely have been a more important time in postwar Europe for the consequences of unemployment for health and welfare to be kept in the attention of health professionals and people alike.

STUART DONNAN

Editor

1 Donnan S, Hobson SJ. Ethics, human rights and the public health. Oxford: Oxford University Press, 1997. In press. 